\title{
Alternatives vs. Time - Measuring the Force of Distinct Sources of Bargaining Power
}

\author{
Niklas Dahlen $^{1(\bowtie)}(\mathbb{D})$ and Tilman Eichstädt ${ }^{2}$ (D) \\ 1 HHL Leipzig Graduate School of Management, \\ Jahnallee 59, 04109 Leipzig, Germany \\ niklas.dahlen@hhl.de \\ ${ }^{2}$ BBW Hochschule, Leibnizstraße 11-13, 10625 Berlin, Germany
}

\begin{abstract}
This study aims to deepen the understanding of the drivers of bargaining power in negotiations and in particular the role of best alternatives (BATNA) and time pressure. Previous experimental negotiation research mainly focused on the power of BATNA and the influence of the context on the negotiation outcome, raising the question as to whether BATNA is indeed the only relevant power lever in negotiations. Especially game theorists have shown that time-related costs have a decisive influence on negotiation outcomes. The study proposes a framework to actually measure and compare the relevance and force of different power levers in a simulated distributive buyer-seller negotiation. The results suggest that time pressure can be as influential as an alternative; however, students and professionals seem to react differently to power manipulations. Whereas the student sample was significantly influenced by time pressure but not by alternatives, the opposite could be observed in the professional group. The findings question the common belief that alternatives are the key driver of power in negotiations.
\end{abstract}

Keywords: Negotiation $\cdot$ Power $\cdot$ Alternatives $\cdot$ Time $\cdot$ Bargaining

\section{Introduction}

With its interface position in social psychology and economics, negotiation research touches upon many areas of viable research including that of Nobel laureates such as Kahneman and Nash or renowned researchers such as Rubinstein and Ury [24, 38, 70]. While many articles deal with some effects of power, only limited attention is paid to the actual source of this negotiation power. On the whole, most authors agree that negotiation power is the driving force, both with regard to negotiation processes and outcome [27]. Still beside the most prominent source of negotiation power, alternatives, limited attention has been paid to other power sources and their interaction. That said, there is still a lack of systematic research into the drivers of bargaining power, which is reflected by Agndal et al. [2] who state: "A few studies address the issue of power [...]." [2, p. 11]. However, recently several authors have looked into the variety of sources of negotiation power and their respective interdependency [6, 18, 27, 37]. At the same time, we are observing a period where negotiation experts are increasingly concerned with the abuse of power negotiations by international politicians. 
The Negotiation Journal of the program on negotiation of the Harvard Law School dedicated a whole special issue in early 2019 to the potential impact of President Trumps approach to hard bargaining and the unilateral use of power in negotiations [13]. In this context, Pruitt [64] recognizes the need for a better understanding of the role of time in negotiations.

While power is a multifaceted concept and individual threads of research exist, the basic foundations were laid by French and Raven [26, 68] and Emerson [21]. Within negotiation research, authors have contributed in different fields with very specific concepts such as Rubinstein [59, 70], Nash in game theory [54, 55] and Fisher and Ury in conflict resolution [24]. Howard Raiffa is regarded to be the first to establish a comprehensive and cross-disciplinary approach to negotiation research $[65,66]$ where he identified time and information as potential sources of power alongside the importance of alternatives. Building upon this, Eichstädt et al. [18] very recently provided a first approach to compare drivers of negotiation power. In parallel, Galinsky et al. [27] added status and social capital to the list of potential negotiation power drivers.

Many researchers state that negotiation power is solely defined by the "best alternative to a negotiated agreement", the so-called BATNA. The simple intuition here is that the better one's alternatives, the better one's position of power in a negotiation [71]. The obvious appeal of this concept has resulted in a certain lack of empirical studies that examine power drivers beyond the BATNA concept, thereby hampering the assessment of the strength of individual power drivers [42, 46]. This is confirmed by Agndal et al. [2] who list only six (1.2\%) relevant studies in a meta-analysis of 490 studies on business negotiations. Moreover, the studies do not shed light on the drivers of bargaining power but rather on the effects of having power [2]. Unfortunately, there is not even a reliable framework to measure negotiation power or compare the force of different sources of power. In view of this, the strengths of distinct bargaining power drivers have not been compared to each other systematically [7].

Following the thoughts of Galinsky et al. [27], this paper focuses on comparing two distinct sources of power: alternatives and time. Time plays an especially vital role in most buyer-supplier contracts. Typically, one side has a bigger interest to close the contract and win the business. Maybe it is a buyer to ensure production needs to start soon, or maybe it is a sales agent, trying to ensure he gets his bonus. In Just-in-Time based industries, companies put themselves under the risk of coming under heavy pressure of suppliers, if they threaten to stop supply briefly [63]. In project-based industries, such as the energy sector and wind farm construction, delivery timing forms an essential part of contracts and requires special attention throughout the respective project [15]. The importance of time is also highlighted by professional negotiation advisors who are very successful in negotiation consulting, but do not actively publish in the scientific arena [28, 82]. In order to facilitate the analysis and comparison of power levers in negotiations, we propose a simple concept allowing the magnitude of different power levers to be evaluated by manipulating the levers across otherwise stable experimental settings. Moving towards the empirical study, the paper firstly provides a definition of social power before taking a look at the concepts at hand when it comes to alternatives and time in negotiation research. In doing so, attention is directed at the experimental design of previous studies. Our experimental design aims 
to incorporate the findings from previous studies while remaining realistic so as not to dilute practical implications. In this way, a dyadic, multi-issue and face-to-face buyerseller negotiation is simulated. The paper closes with the derivation of theoretical and practical implications and suggests ways to further explore the driving forces of negotiation power.

\section{Theoretical Background}

Definition of Power. Power is the regulative mechanism of our existence defining the lines of human interaction and thus driving business interactions as well [84]. Max Weber defined power as: "the possibility of imposing one's will upon the behavior of other persons" [86, p. 21]. Keltner et al. [39] sharpen the understanding by saying that it is one's relative ability to change others' attitudes [39, 40]. In particular, the relational aspect of power cannot be stressed enough; it is the cornerstone of Emerson's power dependence theory and also the key to Dahl's concept of power $[14,21]$. The first question regarding the origin of power has been discussed extensively in literature and received a comprehensive and continuously evolving framework from French and Raven. However, the effects of various power instruments in negotiations received limited attention, especially in the field of management. Only very recently have Reimann, Shen and Kaufmann [69] looked into the effects of power use in buyersupplier relationships and the use and effects of applying coercive power [69].

Alternatives and BATNA in Negotiation. Most individuals intuitively agree that having an alternative in a negotiation increases one's power. In his power dependence theory, Emerson laid the groundwork for the BATNA concept as he states that one's power is subject to mutual dependence on each other [21-23]. Consequently, having an alternative unilaterally reduces the dependence of one stakeholder and thus increases his/her bargaining power. A large number of studies have investigated the impact of alternatives in negotiation with different moderating factors pointing to the conclusion that alternatives improve one's position of power. Nevertheless, the variance in experimental setting makes it hard to compare the different and sometimes contradictory results. Moreover, even though the concept of BATNA seems to be rather simplistic, the operationalization is not and Sebenius states that BATNA can be "problematic, limiting and even misleading" [72, p. 1].

Over recent decades, BATNA has been operationalized in many ways but no systematic approach dominates research. These manipulations led to a variety of findings which are ambiguous in some respects [41]. In particular, a lively discussion has formed on the effect of alternatives in terms of the integrativeness of an agreement [89]. Sondak and Bazerman [74] and later Pinkley et al. [62] concluded that an asymmetric power structure leads to a better joint outcome. Both studies involved a job contract negotiation and were conducted with graduate students but their manipulation was slightly different in that three conditions (high, low or no BATNA) were included in the study of Pinkley et al. [62] contrasted with two BATNA conditions in the study of 
Sondak and Bazerman [74]. The opposing camp argues that a symmetric power structure leads to a better joint outcome because the frequency of exchange is increased which generates more positive emotions [45, 49].

Multiple studies have dealt with situational factors which can be grouped into three categories: 1) Negotiator's characteristics, 2) Negotiator's decision making, and 3) Other endogenous factors. Studies in the first category involve the impact of emotions [81], social motivation [29, 88], self-efficacy and goal orientation [1, 6]. The studies show that emotions alter concession-making behavior and that an individualistic vs. pro-social motivation leads to more or less competitive negotiation behavior [29, 81]. Having a specific goal or self-efficacy or even both leads to a better individual outcome [1]. Studies on the effect of risky choices [44], choice of negotiation tactic [4] and initiation of the negotiation [47] fall into the second category [43]. Especially noteworthy is the finding of Magee et al. [47] which shows that high-power negotiators are more likely to make the first offer. The final category encompasses endogenous factors that are not directly influenced by the negotiating parties themselves. The studies include the impact of the role of negotiators, size of the bargaining zone, initial offer, and knowledge of the power and quality of BATNA [11, 17, 30, 61, 85]. For the paper at hand, the impact of role is especially interesting and is reviewed by Olekalns [58] who concludes that under equal conditions buyers outperform sellers in terms of profit per transaction, total profit, and number of transactions [5, 20, 57]. Similarly, Neale et al. [36] support this finding by saying that buyers outperform sellers in symmetrical power negotiation in which they manipulated the role information of the parties [36]. Moreover, Eliashberg et al. [20] showed that buyers are perceived as having more power than sellers and reach higher profits in a buyer-seller negotiation on ski caps. In brief, the finding that buyers outperform sellers seems to be robust, as shown by the manipulation of moderating factors such as goal setting or framing [36, 48]. In addition to this, an interesting study by Schaerer et al. [71] demonstrated that having multiple alternatives might actually decrease your individual outcome.

All the above-mentioned studies show that alternatives in negotiation are, at first glance, a well-researched topic. Still, they do not answer the question as to whether and to what extent alternatives are a main driver of bargaining power. Additionally, in the review of Agndal et al. [2] alternatives are neither directly related to power in negotiation nor covered in a separate chapter, which indicates that little attention is paid to alternatives as a source of bargaining power.

Time in Negotiation. Even though time dictates the rhythm at which the world operates, it did not receive much attention in negotiation context until 1985. Back then, game theorist Ariel Rubinstein formalized an abstract idea into a concrete concept of either fixed bargaining costs per round or time-dependent costs that reflect the preferences of the negotiating parties. In the case of fixed bargaining costs, the parties would arrive at an equilibrium because the party with greater time preference would settle immediately in order to avoid unnecessary costs. In contrast, Rubinstein [70] describes time-dependent costs in terms of a discount factor $\delta_{i}^{t} \leq 1$. This would mean that after two negotiation rounds, party 1 would receive $\delta_{1}^{2} \mathrm{x}$ and party 2 would receive $\delta_{2}^{2} \mathrm{x}$. The party with the lower discount factor therefore has an advantage and can use this against the more impatient party $[59,67,70]$. 
The cost per round described above is by no means the only trigger of time pressure. Equally well known are approaching deadlines [32, 50, 51, 60]. Additionally, time pressure can arise from threats [73], intervention of third parties [3] or the value of other opportunities for negotiators [12]. While people certainly react differently to time pressure, it is assumed that three strategies to cope with it are applied: 1) Acceleration To accelerate information processing, 2) Filtration - To only select information perceived as important for processing, and 3) Omission - To use cognitive heuristics and apply a damage minimization strategy [9, 31, 33, 38, 76, 87].

Despite the undisputable importance of time in negotiation research, Rubinstein's pioneering work was neither the starting point for a series of game-theoretical contributions to time pressure in negotiation nor the kick-off of systematic research in another negotiation research field. Looking at the game-theoretical contributions to this topic, Mosterd and Rutte [53] found out that negotiators who act on behalf of somebody else negotiate more competitively under high time pressure. Similarly, Sutter, Kocher and Strauß [78] examined the effect of time pressure on negotiation behavior and saw that the rejection rates increased under high time pressure. They therefore concluded that time pressure in situations that are new to the parties involved leads to losses in efficiency. In the same year, Gneezy, Haruvy and Roth [32] showed that agreements are usually reached at the end of a deadline. While all of the gametheoretical results give us an indication about the general perception of time pressure and its influence on a negotiation, the generalizability of the findings to real-world negotiations is limited due to their specific assumptions (e.g. complete information) and negotiation setting (e.g. ultimatum game).

Non-game-theoretical studies attempted to examine the following: 1) Effect of time pressure and motivational orientation on integrative negotiation [8], 2) Effect of time pressure and information on the negotiation process [77], 3) Effect of time pressure on information processing [16], and 4) Effect of revealing time pressure on the actual outcomes [52]. Even though Carnevale and Lawler [8] and De Dreu [16] applied different negotiation settings, both studies suggest that time pressure and an individualistic orientation lead to more impasses and in general more competitive behavior. Additionally, Stuhlmacher and Champagne [77] demonstrated with their experiment that time pressure reduces the response time and that having additional information about the other party leads to a negotiation advantage [77]. An interesting and at first glance counterintuitive result is provided in studies of Moore [52]. The studies showed that revealing a deadline has a positive impact on the negotiation outcome because the concession making is faster and less time is wasted as a result.

Consequently, the studies on time pressure in negotiation provide valuable insights but they do not offer a definitive answer that can be applied to all scenarios. Additionally, the operationalization of time pressure is not addressed in a concise way, which calls into question the validity of some of the results. The fact that only the study of Moore [52] simultaneously imposed time costs and deadlines is especially troublesome. The lack of systematic research is also documented by the study of Agndal et al. [2] which shows that only nine out of 490 studies involved time pressure in negotiation. The research gap is widened when one considers the limited use of professionals and typical buyer-seller negotiation settings. There is therefore no study that manipulates time pressure in a buyer-seller negotiation with multiple negotiation issues involving students and professionals as participants. 


\section{Empirical Study}

\subsection{Method}

Negotiation Setting. In order to test the initial hypothesis, a face-to-face negotiation was simulated based on a real-life negotiation on the purchase/sale of corrugated boxes. The experiment includes 50 participants negotiating one on one, of which $68 \%$ were male and $32 \%$ were female. It was conducted at HHL Leipzig Graduate School of Management and within the scope of an executive training program for HelloFresh AG, which means that a student sample and a professional buyer sample were involved in the experiment. The students were motivated by offering them the possibility to exchange their negotiated outcome for pens of varying quality. The professionals were motivated by both the distribution of chocolate coins based on their performance as well as their fear of losing face in front of their colleagues. The best negotiators were announced publicly and received special recognition of their achievement by the senior management. Additionally, at the beginning of the experiment it was stressed that their performance would be measured based on their individual results. This amplified the individualistic orientation of the participants. In order to reduce the effects of cognitive biases, individuals received an introduction to behavioral economics including the anchoring and framing effect. The parties did not receive any information on their opponents such as age, previous education, etc., as it was assumed that the exposure to the specific negotiation setting was comparable for both negotiation training courses (at HHL Leipzig Graduate School of Management or as part of the executive training program). However, professional buyers in the executive training program had a generally larger exposure to professional negotiations than the students (Professional buyers and students were not mixed in the experiment). Prior to the negotiation, the setup was tested with several dyads with students from HHL Leipzig Graduate School of Management in order to calibrate the time cost and the alternative. Generally, the setting followed an experiment conducted by Eichstädt et al. [18] who applied different power manipulations in executive training programs in the automotive sector. In contrast to the earlier experiments, the following experiment tested more significant manipulations of time costs and compared the negotiation outcome of having increased time costs with having a BATNA.

Negotiation Task. Simulating a real-life negotiation, the participants were randomly assigned to one of two roles (buyer or seller) and had to negotiate the following three issues: price (for 10 pieces in $€$ ), payment (days), and minimum order quantity per week. The negotiation was largely based on a real case that was conducted a while ago at HelloFresh. Participants were placed directly opposite one another and were allowed to communicate freely and exchange all the given information. The design aims to be as close as possible to a real negotiation in order to increase the ecological validity and with that the relevance of the implications.

Negotiation Rounds. The experiment extends over three negotiation rounds which lasted a maximum of $15 \mathrm{~min}$ and involved time costs amounting to 0.25 points per minute (excluding the third case). The dyads were not mixed in between the rounds. During the different rounds, the following manipulations were applied: 
- $\mathbf{1}^{\text {st }}$ round: No manipulation - Parties received information about their own reservation points.

- $2^{\text {nd }}$ round: Manipulation of alternative - Buyers ould exit the negotiation and take an alternative worth $75 \%$ of the available ZOPA. Sellers did not know about the alternative and did not receive one.

- $3^{\text {rd }}$ round: Manipulation of time pressure - Time costs were doubled for buyers reaching 0.5 points per minute. Time costs for sellers were not changed $(0.25$ points per minute). Parties received no alternative (BATNA).

Dependent Variable. Performance was solely measured based on the payoff structure, which was determined by the ZOPA and the required time. In other words, the party who is able to claim most of the ZOPA in the shortest amount of time achieves the best outcome. A maximum of 10 points representing $100 \%$ of the ZOPA could be reached per round. If the parties did not reach an agreement within $15 \mathrm{~min}$ or decided to end the negotiation without an agreement, zero points were awarded. Assuming that a seller claims $60 \%$ of the ZOPA within five minutes, an outcome of 4.75 points would be reached (six points from ZOPA - 1.25 points time cost; see Fig. 1). Payoffs were symmetric so that there was no specific integrative solution and the negotiation was purely distributive.

\begin{tabular}{|c|c|c|c|c|}
\hline$\%$ of ZOPA & Points awarded & $\begin{array}{l}\text { Required } \\
\text { time }\end{array}$ & $\begin{array}{l}\text { Time } \\
\text { costs }\end{array}$ & $\begin{array}{l}\text { Exemplary } \\
\text { Outcome }\end{array}$ \\
\hline$>10 \%$ & 0 & 1 & 0.25 & \multirow{16}{*}{$\begin{array}{l}>70 \% \text { of ZOPA } \\
\text { and } \\
5 \text { minutes required }\end{array}$} \\
\hline$>20 \%$ & 1 & 2 & 0.50 & \\
\hline$>30 \%$ & 2 & 3 & 0.75 & \\
\hline$>40 \%$ & 3 & 4 & 1.00 & \\
\hline$>50 \%$ & 4 & 5 & 1.25 & \\
\hline$>60 \%$ & 5 & 6 & 1.50 & \\
\hline$>70 \%$ & 6 & 7 & 1.75 & \\
\hline$>80 \%$ & 7 & 8 & 2.00 & \\
\hline$>90 \%$ & 8 & 9 & 2.25 & \\
\hline$>100 \%$ & 9 & 10 & 2.50 & \\
\hline \multirow[t]{6}{*}{$100 \%$} & 10 & 11 & 2.75 & \\
\hline & & 12 & 3.00 & \\
\hline & & 13 & 3.25 & \\
\hline & & 14 & 3.50 & \\
\hline & & 15 & 3.75 & \\
\hline & & & 4.00 & \\
\hline
\end{tabular}

Fig. 1. Payoff matrix. Source: Own illustration.

Power Manipulation. In the second round, buyers received an alternative representing $75 \%$ of the ZOPA. The fairly good option of receiving $75 \%$ of the ZOPA was chosen to ensure that negotiators perceive the alternative as attractive. This manipulation was chosen to give one party substantial leverage stemming from an alternative 
but still leaving scope to gain a superior result with the opposing party. Additionally, the design ensured easy comprehensibility of the alternative by handing the exact features of the alternative to the participants and not manipulating the likelihood of receiving the alternative [62].

In the third and final round, time costs were altered. Imposing time costs rather than manipulating the deadline was chosen because of three major shortcomings of deadlines. First and foremost, deadlines can only be symmetric which means that if one party stops negotiating then the negotiation ends for both parties [52]. Moreover, deadlines are perceived very differently and thus the resulting behavior varies $[50,75]$. In this regard, buyers had to negotiate under twice as much time costs as sellers in this experiment and so 0.5 points per minute were deducted from their result. This approach is based on the reasoning of the Rubinstein model but uses penalties instead of discounting to simplify the decision making for participants. Pretests within the range of manipulation of previous studies were used to calibrate alternatives and time pressure.

\subsection{Results}

Preliminary Note. The results for the professional and student groups are reported separately using an Analysis of Variance (ANOVA). The effects of the manipulation of time and alternatives are shown in Table 1 and Table 2. These illustrate means of negotiated agreement, role of negotiators, number of dyads, standard deviations, Fstatistics, and p-values.

Manipulation Check. ${ }^{1}$ After the actual negotiation, participants were asked to fill out a short questionnaire revealing their perceived relative power and time pressure (from "very low" to "very high") across the different cases. The perceived power shows that buyers report significantly higher power in the alternative case than sellers, which indicates a successful manipulation (Buyer: $\mathrm{M}=7.63, \mathrm{SD}=1.996$; Seller: $\mathrm{M}=2.94$, $\mathrm{SD}=1.731 ; \mathrm{F}(1,30)=50.373, \mathrm{p}<0.000)$. In the same manner, the results reveal a successful manipulation of time pressure because buyers report significantly higher perceived time pressure in the last case (Buyer: $\mathrm{M}=8.88, \mathrm{SD}=.885$; Seller: $\mathrm{M}=2.44, \mathrm{SD}=1.672 ; \mathrm{F}(1,30)=185.256, \mathrm{p}<0.000)$. Similarly, sellers report higher perceived power in the last case in which buyers are under time pressure (Buyer: $\mathrm{M}=3.06, \mathrm{SD}=1.436$; Seller: $\mathrm{M}=6.25, \mathrm{SD}=1.949 ; \mathrm{F}(1,30)=27.729, \mathrm{p}<0.000)$.

Effects of Manipulation of Alternatives on Negotiated Outcome. The manipulation of alternatives leads to a better performance of buyers in the student group but the effect is not significant (Seller: $\mathrm{M}=2.7656, \mathrm{SD}=4.9273$; Buyer: $\mathrm{M}=3.2403, \mathrm{SD}=$ 3.2403; $\mathrm{F}(1,30)=0.550, \mathrm{p}=0.464)$.

In contrast to this, a significant result can be observed in the professional group. Buyers outperform sellers and score a mean negotiated outcome of 3.69 while sellers only reach 1.44 (Seller: $\mathrm{M}=1.4444$, $\mathrm{SD}=2.1278$; Buyer: $\mathrm{M}=3.6944$,

\footnotetext{
${ }^{1}$ Due to time constraints, no self-assessment was conducted for the executive training program at HelloFresh. Consequently, the manipulation check is limited to the student sample.
} 
$\mathrm{SD}=2.6832 ; \mathrm{F}(1,16)=3.885, \mathrm{p}=0.066)$. Additionally, the buyers in both groups performed better having a BATNA compared to the base case.

The findings thus indicate that professionals and students cope differently with the manipulated situation. Professional buyers seem to be able to make better use of alternatives than students.

Effects of Manipulation of Time on Negotiated Outcome. An opposing result in the student and professional groups can be observed here too. Buyers in the student sample who are under severe time pressure are outperformed by their opponent (Seller: $\mathrm{M}=4.2813, \mathrm{SD}=2.3235 ;$ Buyer: $\mathrm{M}=1.9224, \mathrm{SD}=1.9224 ; \mathrm{F}(1,30)=5.980$, $\mathrm{p}=0.021$ ). This does not hold true for the professional sample in which buyers outperform sellers regardless of their time pressure (Seller: $\mathrm{M}=2.111, \mathrm{SD}=2.8038$; Buyer: $\mathrm{M}=3.333, \mathrm{SD}=3.3166 ; \mathrm{F}(1,16)=0.713, \mathrm{p}=0.411)$. Additionally, the sellers in both groups performed better having less time pressure compared to the results of the base case.

Consequently, time pressure has a significant effect on the performance of negotiators in the student sample while professionals seem to be able to counteract the pressure.

Table 1. Results of student sample

\begin{tabular}{l|l|l|r|l}
\hline Student group (total of 32 participants or 16 dyads) \\
\hline Manipulation & Mean (standard deviation) & F-ratio & p-value \\
\hline & Seller & Buyer & & \\
\hline Base & $3.9844(3.52428)$ & $1.5000(2.03715)$ & 5.960 & .21 \\
\hline Alternative favoring the buyer & $2.7656(4.92736)$ & $3.24033(3.24033)$ & .550 & .464 \\
\hline Time pressure favoring the seller & $4.2813(2.32357)$ & $1.92246(1.92246)$ & 5.980 & .021 \\
\hline
\end{tabular}

Table 2. Results of professional sample

\begin{tabular}{|c|c|c|c|c|}
\hline \multicolumn{5}{|c|}{ Professional group (total of 18 participants or 9 dyads) } \\
\hline \multirow[t]{2}{*}{ Manipulation } & \multicolumn{2}{|c|}{ Mean (standard deviation) } & \multirow[t]{2}{*}{ F-ratio } & \multirow[t]{2}{*}{ p-value } \\
\hline & Seller & Buyer & & \\
\hline Base & $1.0833(1.9243)$ & $2.3611(2.6900)$ & 1.343 & .263 \\
\hline Alternative favoring the buyer & $1.4444(2.1278)$ & $3.6944(2.6832)$ & 3.885 & .066 \\
\hline Time pressure favoring the seller & $2.111(2.8038)$ & $3.333(3.3166)$ & .713 & .411 \\
\hline
\end{tabular}

\section{Discussion}

The findings are important, both from a practical and a theoretical perspective. Most significantly they sharpen the understanding of drivers of bargaining power and compare their strength. By doing so, the results provide valuable insights for 
negotiators into the effects of time pressure and negotiation. Moreover, the experiment shows that students and professionals react differently to power manipulations which highlights the importance of negotiation training. From a theoretical perspective, the paper expands on the thoughts of conceptual papers, for example those of Galinsky et al. [27] and Fleming and Hawes [25]. Additionally, the novel experimental setting contributes to general negotiation research and the ongoing discussion on the validity of student-based experiments.

Practical Implications. The results of previous research have shown that power has a decisive impact on the negotiated result. Additionally, power is a key driver determining many buyer-supplier relationships (BSRs) where we often find a situation where one party (a supplier or buyer) can dominate the relationship based on a better position of power and less dependence [79]. With the identification of two drivers of bargaining power, time pressure and alternatives, the study sensitizes negotiators to the importance of assessing the impact of both on their individual position of power. In fact, an interesting real-life example of managers underestimating the effect of time on the power balance in negotiations could be observed in the German automotive industry in 2016. The relatively small supplier Prevent forced Europe's biggest carmaker Volkswagen to shut down its plants for almost a week by stopping supply after Volkswagen refused to pay for investments in a joint project (VW says 6 plants hit by production stoppages, 2016) $[63,83]$. Ultimately, the final agreement was perceived as a bad deal for Volkswagen and a big success for Prevent and shows that negotiation outcomes are not just driven by classical definitions of power like size, economic power and potential to use coercion and reward [69].

Overall, the fact that both time and alternatives influence negotiation power to a certain extent underlines the opportunity for buyers and sellers to develop negotiation strategies, which strengthens their relative power along these lines. The effect of time pressure indicates that managers should pay special attention to the scheduling of negotiations and time management within negotiation. One can create artificial deadlines by defining a specific schedule for the negotiation or scheduling the departure of the negotiation team. While time pressure is perceived by most people as problematic and limiting, it is a two-edged sword which might have an upside. If the negotiation itself creates value for both parties then finding an agreement as fast as possible is beneficial for the two of them [52].

The specific experimental setting involving students and professionals gives us the opportunity to compare their behavior. Students were more affected by the power manipulations which indicates that experience and training are important to withstand an inferior negotiation setting of time pressure or having no alternative. In this way, the study highlights the importance of negotiation training for professional buyers and sellers. The lack of systematic negotiation training is also highlighted in a study by Herbst and Voeth [35] which states that $70 \%$ of all respondents did not receive any. In addition, $62 \%$ of the surveyed executives stated that they were not prepared for upcoming negotiation tasks by their employer.

Theoretical Implications. In theoretical terms, the most important contribution of the study lies in the investigation of drivers of bargaining power. It is the first study to address the question of which power lever is the strongest. Nonetheless, the findings 
are not unambiguous since a tendency can be observed that alternatives seem to have an effect in both groups. While students appear to be especially affected by time pressure, professionals can adjust to it and make better use of the provided alternative. This raises the question as to whether experience on the part of the negotiators actually influences the force and impact of negotiation power. The results could indicate that more experienced and professional negotiators benefit from two effects. Firstly, they are able to better use negotiation power with regard to alternatives to their advantage and, secondly, it seems that they are less easily influenced by time pressure to make significant concessions too willingly.

The novelty of the study at hand is also emphasized when looking at the conceptual paper of Galinsky et al. [27]. They state that while there are many studies on the effect of power, there is no common understanding of what power actually is. Based on a literature review, they define alternatives, information, status and social capital as sources of bargaining power. Our study builds on those findings by adding time as a fifth source of bargaining power and gives an empirical foundation for defining alternatives and time as drivers of bargaining power [27]. It also provides a framework to actually measure the relevance of different sources of power, which can additionally be applied to compare those drivers identified by Galinsky et al. [27].

In an article recently published by Fleming and Hawes [25], a negotiation scorecard consisting of 14 situational factors is described which should help to identify an appropriate negotiation strategy. While the authors name timing and power as a determinant of one's strategy, they fail to describe the driving forces behind power and thus complicate the applicability of their concept. Our finding that both time and alternatives are key drivers of bargaining power helps to substantiate the conceptual thoughts and the applicability of the scorecard [25]. Together with a broader assessment of power sources, it could be a useful extension of the scorecard which would help to assess the position of power in advance.

With this considered, the study not only contributes to power in negotiation itself but also to the discussion as to whether student-based experiments are appropriate by applying the same negotiation task to a group of students and professional buyers. Herbst and Schwarz [34] have shown that untrained students are outperformed by experienced managers as well as trained students. While our experiment yields comparable evidence, the novelty lies in the negotiation setting. Instead of an online negotiation which might distort the negotiation results, we applied a face-to-face negotiation. Additionally, we manipulated power levers (time and alternatives) to imitate a real negotiation in which power asymmetries exist. The importance of negotiation experience is also shown by a meta-analysis conducted by ElShenawy [19] which demonstrates that negotiators with extensive negotiation training perform better.

The importance and novelty of this design is also supported by the results of Agndal et al. [2] who point out that only $5.7 \%$ of negotiation studies involve both students and professionals. Looking solely at simulations and experiments, only $2.7 \%$ (five out of 192 ) include students and professionals. Moreover, none of the five studies involves a setting in which alternatives and/or time are manipulated. 
In addition to this, the findings are important because the experimental design is based on a real negotiation, which gives the participants context. The results thus offer greater relevance compared to experiments based on completely artificial settings [10, $56,80]$.

Limitations. Even though the experimental design aimed to incorporate the findings of previous studies, the results must be couched in the caveats of laboratory experiments.

Firstly, the design incorporated only three issues to ensure that the context is easily understandable for everyone. This setting cannot always be observed in reality where buyer-seller negotiations are much more complex and involve a higher number of issues to be negotiated which can hardly be measured on a scale. Secondly, the negotiation was a one-on-one negotiation, meaning that the negotiators were not able to discuss their approach with other individuals. In a typical buyer-seller negotiation, the parties consist of multiple individuals and often multiple rounds, so the decision making might be altered.

Furthermore, the magnitude of calibration of the power manipulation can be discussed because for both manipulations strong empirical evidence or systematic research is missing. As the time manipulation depends on whether a party actually perceives time pressure, it is especially cumbersome to manipulate it in a way that all participants perceive time pressure. Additionally, it could be insightful to include a more thorough analysis of the influence of time pressure on satisfaction or the perceived relationship. Finally, over the course of three rounds of negotiations, learning effects might occur which distort the behavior of the later rounds compared to that of the first.

Future Research. This study is a stepping stone towards a systematic investigation of the different power levers in negotiations. In order to improve the validity of results, several measures need to be taken. Firstly, the experiment should be extended to a higher number of participants from both groups of students and professionals. In addition, it would be recommended to actually measure and quantify the amount of experience, status and knowledge the professionals have in order to test if this alters the impact of negotiation power in line with the findings of Galinsky et al. [27]. Secondly, research on the perception of time pressure and alternatives should be intensified in order to derive a comprehensive approach and calibrate those drivers for research. Thirdly, we have to keep in mind that buyer-seller negotiations always involve humans and the perception of power is thus central to understanding power. Additional research on perception could clarify the underlying cognitive mechanism and help negotiators in their preparations. Finally, additional research should broaden the consideration of other power drivers such as information or social capital to examine their effect and relative strength. The methodology laid out could be easily adapted to measure the impact of sources of negotiation power as put forth by Galinsky et al. [27]. 


\section{References}

1. Adair, W.L., Brett, J.M.: The negotiation dance: time, culture, and behavioral sequences in negotiation. Organ. Sci. 16(1), 33-51 (2005). https://doi.org/10.1287/orsc.1040.0102

2. Agndal, H., Åge, L., Eklinder-Frick, J.: Two decades of business negotiation research: an overview and suggestions for future studies. J. Bus. Ind. Mark. 32(4), 487-504 (2007). https://doi.org/10.1108/JBIM-11-2015-0233

3. Arunachalam, V., Dilla, W., Shelley, M., Chan, C.: Market alternatives, third party intervention, and third party informedness in negotiation. Group Decis. Negot. 7(2), 81-107 (1998). https://doi.org/10.1023/A:1008606709761

4. Bacharach, S.B., Lawler, E.J.: Power and tactics in bargaining power and tactics in bargaining. Labor Relat. Rev. 34(2), 219-233 (1981)

5. Bazerman, M.H., Magliozzi, T., Neale, M.A.: Integrative bargaining in a competitive market. Organ. Behav. Hum. Decis. Process. 35(3), 294-313 (1985). https://doi.org/10.1016/ 0749-5978(85)90026-3

6. Brett, J.F., Pinkley, R.L., Jackofsyk, E.F.: Alternatives to having a BATNA in dyadic negotiation: the influence of goals, self-efficacy, and alternatives on negotiated outcomes. Int. J. Confl. Manag. 7(2), 121-138 (1996). https://doi.org/10.1108/eb022778

7. Buelens, M., Van De Woestyne, M., Mestdagh, S., Bouckenooghe, D.: Methodological issues in negotiation research: a state-of-the-art-review. Group Decis. Negot. 17(4), 321-345 (2008). https://doi.org/10.1007/s10726-007-9097-3

8. Carnevale, P.J.D., Lawler, E.J.: Time pressure and the development of integrative agreements in bilateral negotiations. J. Conflict Resolut. 30(4), 636-659 (1986)

9. Carenevale, P.J., O'Connor, K.M., McCusker, C.: Time pressure in negotiation and mediation. In: Svenson, O., Maule, A.J. (eds.) Time Pressure and Stress in Human Judgment and Decision Making, pp. 117-127. Springer, Boston (1993). https://doi.org/10.1007/978-14757-6846-6_8

10. Carnevale, P.J.D., De Dreu, G.K.W.: Methods of Negotition Reserch. Martinus Nijhoff Publishers, Leiden (2006)

11. Conlon, D.E., Pinkley, R.L., Sawyer, J.E.: Getting something out of nothing: Reaping or resisting the power of a phantom BATNA. In: Ayoko, O.B., Ashkanasy, N.M., Jehn, K.A. (eds.) Handbook of Conflict Management Research. Edward Elgar Publishing, Cheltenham (2014)

12. Cross, J.: A theory of the bargaining process. Am. Econ. Rev. 55(1), 67-94 (1965). http:// www.jstor.org/stable/10.2307/1816177

13. Cutcher-Gershenfeld, J., Druckman, D., Manwaring, M., Menkel-Meadow, C., Waters, N.J.: Negotiation and conflict resolution in the age of Trump. Negot. J. 35(1), 5-8 (2019)

14. Dahl, R.: The concept of power. Behav. Sci. 2(3), 201 (1957). https://doi.org/10.1002/bs. 3830020303

15. D'Amico, F., Mogre, R., Clarke, S., Lindgreen, A., Hingley, M.: How purchasing and supply management practices affect key success factors: the case of the offshore-wind supply chain. J. Bus. Ind. Mark. 32(2), 218-226 (2017). https://doi.org/10.1108/JBIM-10-20140210

16. De Dreu, C.K.W.: Time pressure and closing of the mind in negotiation. Organ. Behav. Hum. Decis. Process. 91(2), 280-295 (2003)

17. Dwyer, F., Walker, O.: Bargaining in an asymmetrical power structure. J. Mark. 45(1), 104115 (1981) 
18. Eichstädt, T., Hotait, A., Dahlen, N.: Bargaining power - measuring it's drivers and consequences in negotiations. Group Decis. Negot. 274, 89-100 (2017). https://doi.org/10. 1007/978-3-319-52624-9_7

19. ElShenawy, E.: Does negotiation training improve negotiators' performance? J. Eur. Ind. Train. 34(3), 192-210 (2010)

20. Eliashberg, J., LaTour, S.A., Rangaswamy, A., Stern, L.W.: Assessing the predictive accuracy of two utility-based theories in a marketing channel negotiation context. J. Mark. Res. 23(2), 101-110 (1986). https://doi.org/10.2307/3151657

21. Emerson, R.M.: Power-Dependence Relations. Source Am. Sociol. Rev. 27(1), 31-41 (1986). https://doi.org/10.2307/2089716

22. Emerson, R.M.: Power-dependence relations: two experiments. Sociometry 27(3), 282-298 (1964)

23. Emerson, R.M.: Social exchange theory. Ann. Rev. Sociol. 2, 335-362 (1976)

24. Fisher, R., Ury, W.: Getting to Yes. Random House Business Books, New York (1992)

25. Fleming, D.E., Hawes, J.M.: The negotiation scorecard: a planning tool in business and industrial marketing. J. Bus. Ind. Mark. 30(4) (2017). http://dx.doi.org/10.1108/JBIM-062015-0120

26. French, J.R.P., Raven, B.: The bases of social power. In: Leadership as an Influence Process, pp. 151-157 (1959)

27. Galinsky, A.D., Schaerer, M., Magee, J.C.: The four horsemen of power at the bargaining table. J. Bus. Ind. Mark. 32(4) (2017). https://doi.org/10.1108/jbim-10-2016-0251

28. Gates, S.: The Negotiation Book. Wiley, Chichester (2016)

29. Giebels, E., De Dreu, C., Vliert, E.: Interdependence in negotiation: effects of exit options and social motive on distributive and integrative negotiation. Eur. J. Soc. Psychol. 30(2), 255-272 (2000)

30. Giebels, E., De Dreu, C., Vliert, E.: The alternative negotiator as the invisible third at the table: the impact of potency information. Int. J. Confl. Manag. 9(1), 5-21 (1998)

31. Gino, F., Moore, D.: Why negotiators should reveal their deadlines: disclosing weaknesses can make you stronger. Negot. Confl. Manag. Res. 1(1), 77-96 (2008)

32. Gneezy, U., Haruvy, E., Roth, A.: Bargaining under a deadline: evidence form the reverse ultimatum game. Games Econ. Behav. 45(2), 347-368 (2003)

33. Goldstein, W.M., Einhorn, H.J.: Expression theory and the preference reversal phenomena. Psychol. Rev. 94(2), 236-254 (1987)

34. Herbst, U., Schwarz, S.: How valid is negotiation research based on student sample groups? New insights into a long-standing controversy. Negot. J. 27(2), 147-170 (2011)

35. Herbst, U., Voeth, M.: So verhandeln Deutsche Manager. Harvard Bus. Manag. 1, 12-15 (2018)

36. Huber, V.L., Northcraft, G.B., Neale, M.A.: The framing of negotiations: contextual versus task frames. Organ. Behav. Hum. Decis. Process. 39(2), 228-241 (1987). https://doi.org/10. 1016/0749-5978(87)90039-2

37. Janusch, H.: The interaction effects of bargaining power: the interplay between veto power, asymmetric interdependence, reputation, and audience costs. Negot. J. 34(3), 219-241 (2018)

38. Kahneman, D., Tversky, A.: Prospect theory: an analysis of decision under risk. Econometrica 47(2), 263-291 (1979)

39. Keltner, D., Gruenfeld, D.H., Anderson, C.: Power, approach, and inhibition. Psychol. Rev. 110(2), 265-284 (2003). https://doi.org/10.1037/0033-295X.110.2.265

40. Keltner, D., Van Kleef, G.A., Chen, S., Kraus, M.W.: A reciprocal influence model of social power: emerging principles and lines of inquiry. Adv. Exp. Soc. Psychol. 40(7), 151-192 (2008). https://doi.org/10.1016/S0065-2601(07)00003-2 
41. Kim, P.H., Fragale, A.R.: Choosing the path to bargaining power: an empirical comparison of BATNAs and contributions in negotiation. J. Appl. Psychol. 90(2), 373-381 (2005). https://doi.org/10.1037/0021-9010.90.2.373

42. Kim, P.H., Pinkley, R.L., Fragale, A.R.: Power dynamics in negotiation. Acad. Manag. Rev. 30(4), 799-822 (2005). https://doi.org/10.5465/AMR.2005.18378879

43. Kipnis, D., Schmidt, S.M.: An influence perspective on bargaining within organizations. In: Bazerman, M.H., Lewicki, R.J. (eds.) Negotiating in Organizations, pp. 179-210. Sage, Beverly Hills (1983)

44. Komorita, S., Lapworth, C., Tumonis, T.: The effects of certain vs. risky alternatives in bargaining. J. Exp. Soc. Psychol. 17(6), 525-544 (1981)

45. Lawler, E.J., Yoon, J.: Power and the emergence of commitment behavior in negotiated exchange. Am. Sociol. Rev. 58(4), 465-481 (1993)

46. MacGregor, D.: Time pressure and task adaptation: alternative perspectives on laboratory studies. In: Svenson, O., Maule, A.J. (eds.) Time Pressure and Stress in Human Judgment and Decision Making, pp. 73-82. Plenum Press, New York (1993)

47. Magee, J.C., Galinsky, A.D., Gruenfeld, D.H.: Power, propensity to negotiate, and moving first in competitive interactions. Pers. Soc. Psychol. Bull. 33(2), 200-212 (2007). https://doi. org/10.1177/0146167206294413

48. McAlister, L., Bazerman, M.H., Fader, P.: Power and goal setting in channel negotiations. J. Mark. Res. 23(3), 228-236 (1986)

49. Mannix, E.A., Neale, M.A.: Power imbalance and the pattern of exchange in dyadic negotiation. Group Decis. Negot. 2(2), 119-133 (1993). https://doi.org/10.1007/ BF01884767

50. Maule, A.J., Hockey, G.R., Bdzola, L.: Effects of time-pressure on decision-making under uncertainty: changes in affective states and information processing strategy. Acta Psychologica 104(3), 283-301 (2000). https://doi.org/10.1016/S0001-6918(00)00033-0

51. Maule, A.J., Svenson, O.: Time Pressure and Stress in Human Judgment and Decision Making. Plenum Press, New York (1993). https://doi.org/10.1007/978-1-4757-6846-6

52. Moore, D.A.: The unexpected benefits of final deadlines in negotiation. J. Exp. Soc. Psychol. 40(1), 121-127 (2004). https://doi.org/10.1016/S0022-1031(03)00090-8

53. Mosterd, I., Rutte, G.: Effects of time pressure and accountability to constituents on negotiation. Int. J. Confl. Manag. 11(3), 227-247 (2000). https://doi.org/10.1108/eb022841

54. Nash, J.: Two-person cooperative games. Econometrica 21(1), 128-140 (1953)

55. Nash, J.: The bargaining problem. Econometrica 18(2), 155-162 (1950)

56. Neale, M.A., Simons, T., Thompson, L.: An evaluation of dependent variables in experimental negotiation studies: impasse rates and Pareto efficiency. Organ. Behav. Hum. Decis. Process. 51(2), 273-295 (1992)

57. Olekalns, M., Smith, P.L.: Dyadic power profiles: power-contingent strategies for value creation in negotiation. Hum. Commun. Res. 39(1), 3-20 (2013). https://doi.org/10.1111/j. 1468-2958.2012.01440.x

58. Olekalns, M.: The balance of power: effects of role and market forces on negotiated outcomes. J. Appl. Soc. Psychol. 21(12), 1012-1033 (1991)

59. Osborne, M.J., Rubinstein, A.: Bargaining and markets. Games Econ. Behav. 3 (1990). https://doi.org/10.1016/0899-8256(91)90026-B

60. Pinfari, M.: Time to Agree: Time Pressure and 'Deadline Diplomacy' in Peace Negotiations (2010)

61. Pinkley, R.L., Don, V.: Only the phantom knows: impact of certain, conditional, unspecified and zero alternatives to settlement in dyadic negotiation. In: Academy of Management Annual Meeting Proceedings, pp. 82-86 (1997). https://doi.org/10.5465/AMBPP.1997. 4980890 
62. Pinkley, R.L., Neale, M.A., Bennett, R.J.: The impact of alternative to settlement in dyadic negotiation. Organ. Behav. Hum. Decis. Process. 57(1), 97-116 (1994)

63. Pretzlaff, H.: Experten warnen vor Kettenreaktion bei VW. Stuttgarter Zeitung, 22.8.2017, Stuttgarter Zeitung Verlagsgesellschaft mbH (2016)

64. Pruitt, D.G.: What have we learned about negotiation from Donald Trump? Negot. J. 35(1), 87-91 (2019)

65. Raiffa, H.: The Art and Science of Negotiation. First Harvard University Press, Cambridge (1982)

66. Raiffa, H., Richardson, J., Metcalfe, D.: Negotiation Analysis - The Science and Art of Collaborative Decision Making. First Harvard University Press, Cambridge (2007)

67. Rapoport, A., Erev, I., Zwick, R.: An experimental study of buyer-seller negotiation with one-sided incomplete information and time discounting. Manag. Sci. 41(3), 377-394 (1995)

68. Raven, B.H., Schwarzwald, J., Koslowsky, M.: Conceptualizing and measuring a power Interaction model of interpersonal influence. J. Appl. Soc. Psychol. 28(4), 307-332 (1998)

69. Reimann, F., Shen, P., Kaufmann, L.: Effectiveness of power use in buyer-supplier negotiations: the moderating role of negotiator agreeableness. Int. J. Phys. Distrib. Logist. Manag. 46(10), 932-952 (2016). https://doi.org/10.1108/IJPDLM-11-2015-0278

70. Rubinstein, A.: A bargaining model with incomplete information about time preferences. Econometrica 53(5), 1151-1172 (1985)

71. Schaerer, M., Loschelder, D.D., Swaab, R.I.: Bargaining zone distortion in negotiations: the elusive power of multiple alternatives. Organ. Behav. Hum. Decis. Process. 137, 156-171 (2016). https://doi.org/10.1016/j.obhdp.2016.09.001

72. Sebenius, J.K.: BATNAs in negotiation: common errors and three kinds of no? Negot. J. 33 (2), 89-99 (2017). https://doi.org/10.1111/nejo.12176

73. Sinaceur, M., Neale, M.A.: Not all threats are created equal: how implicitness and timing affect the effectiveness of threats in negotiations. Group Decis. Negot. 14(1), 63-85 (2005). https://doi.org/10.1007/s10726-005-3876-5

74. Sondak, H., Bazerman, M.H.: Power balance and the rationality of outcomes in matching markets. Organ. Behav. Hum. Decis. Process. 50(1), 1-23 (1991)

75. Svenson, O., Benson, L.: On experimental instructions and the inducement of time pressure behavior. In: Svenson, O., Edland, A. (eds.) Time Pressure and Stress in Human Judgment and Decision Making, pp. 157-165. Springer, Boston (1993). https://doi.org/10.1007/978-14757-6846-6_11

76. Stuhlmacher, A.F., Gillespie, T.L., Champagne, M.V.: The Impact of time pressure in negotiation: a meta-analysis. Int. J. Confl. Manag. 9(2), 97-116 (1998). https://doi.org/10. 1108/eb022805

77. Stuhlmacher, A.F., Champagne, M.V.: The impact of time pressure and information on negotiation process and decisions. Group Decis. Negot. 9(6), 471-491 (2000). https://doi. org/10.1023/A:1008736622709

78. Sutter, M., Kocher, M., Strauß, S.: Bargaining under time pressure in an experimental ultimatum game. Econ. Lett. 81(3), 341-347 (2003)

79. Tangpong, C., Michalisin, M.D., Traub, R.D., Melcher, A.J.: A review of buyer-supplier relationship typologies: progress, problems, and future directions. J. Bus. Ind. Mark. 30(2), 153-170 (2015)

80. Teich, J., Korhonen, P., Wallenius, H., Wallenius, J.: Conducting dyadic multiple issue negotiation experiments: Methodological recommendations. Group Decis. Negot. 9(4), 347354 (2000). https://doi.org/10.1023/A:1008793819872

81. Van Kleef, G.A., DE Dreu, C., Pietroni, D., Manstead, S.: Power and emotion in negotiation: power moderates the interpersonal effects of anger and happiness on concession making. Eur. J. Soc. Psychol. 36(4), 557-581 (2006) 
82. Voss, C.: Never Split the Difference, p. 113ff. Penguin Random House, London (2016)

83. VW says 6 plants hit by production stoppages (2016). http://europe.autonews.com/article/ 20160821/ANE/160829995/vw-says-6-plants-hit-by-production-stoppages

84. Wallimann, I., Tatsis, N.C., Zito, G.V.: On Max Weber's definition of power. J. Sociol. 13 (3), 231-235 (1970)

85. White, S., Valley, K., Bazerman, M., Neale, A., Peck, S.: Alternative models of price behavior in dyadic negotiations: market prices reservation prices, and negotiator aspirations. Organ. Behav. Hum. Decis. Process. 57(3), 430-447 (1994)

86. Weber, M.: Wirtschaft und Gesellschaft. Grundriß der verstehenden Soziologie. [Economy and Society. Layout of the interpretive sociology]. Mohr Siebeck, Tübingen (2002)

87. Weenig, M.W.H., Maarleveld, M.: The impact of time constraint on information search strategies in complex choice tasks. J. Econ. Psychol. 23(6), 689-702 (2002). https://doi.org/ 10.1016/S0167-4870(02)00134-4

88. Wei, B., Luo, X.: The impact of power differential and social motivation on negotiation behavior and outcome. Public Pers. Manag. 41(5), 47-58 (2012)

89. Wolfe, R.J., McGinn, K.L.: Perceived relative power and its influence on negotiations. Group Decis. Negot. 14(1), 3-20 (2005). https://doi.org/10.1007/s10726-005-3873-8 